\title{
Serum Amyloid A
}

National Cancer Institute

\section{Source}

National Cancer Institute. Serum Amyloid A. NCI Thesaurus. Code C105940.

A family of apolipoproteins that are associated with high-density lipoprotein particles in the serum. These proteins may play a role in both the acute-phase of inflammation and in cholesterol transport. 